\title{
Effect of Ternary Basicity of Iron Ore-Fluxed Pellets on Melting and Softening Properties in a Blast Furnace
}

\author{
FÁBIO R. SILVA, LEANDRO R. LEMOS, PAULO DE FREITAS NOGUEIRA, \\ and MARCELO BRESSAN
}

\begin{abstract}
The cohesive zone is a region of low permeability in a blast furnace. This study shows the impact of the chemical composition of pellets on the metallurgical processes occurring in this region during the iron ore reduction process. Sixteen pellets containing varying contents of $\mathrm{MgO}, \mathrm{CaO}$, and $\mathrm{SiO}_{2}$ were investigated. The results indicate that increasing the $\mathrm{MgO}$ content of pellets improves their high-temperature properties; e.g., reduction degree and softening temperature. Modern equipment was used to replicate the phenomena that occur in the cohesive zone to measure the softening temperature, pressure drop, and the reduction degree of pellets at elevated temperatures and different pellet basicities. These experimental results were used to develop mathematical correlations between parameters related to high-temperature properties and the ternary basicity of the pellets $\left((\mathrm{CaO}+\mathrm{MgO}) / \mathrm{SiO}_{2}\right)$. Defining such relationships will facilitate evaluating the effects of pellet chemical composition on blast furnace processes.
\end{abstract}

https://doi.org/10.1007/s11663-020-01917-6

(C) The Author(s) 2020

\section{INTRODUCTION}

THE deformation of solid-phase particles is vital for understanding the mechanism of softening and melting of the metallic burden. Previous studies focused on the movement behavior of wüstite. ${ }^{[1,2]}$ Laboratory testing demonstrated that it is possible to evaluate the influence of the liquid phase on the microstructure in a wüstite/fayalite system. ${ }^{[3]}$ Softening begins when a liquid phase forms within the microstructure of a reduced particle and not by deformation of the solid phase. Using samples that represent the core without the outer metallic layer, studies have shown that the presence of a liquid phase favors deformation, whereas increasing the amount of liquid phase inside the sample increases the deformation rate. These results suggest that the mechanism is directly related to the microstructure that forms after fusion. ${ }^{[4]}$ The liquid phase acts as a lubricant between wüstite globules and facilitates deformation. In

FÁBIO R. SILVA and LEANDRO R. LEMOS are with the Department of Material and Metallurgical Engineering, Universidade Federal de Minas Gerais, Av. Pres. Antônio Carlos, 6627, Belo Horizonte, 31270901 Brazil. contact e-mail: fabio.rocha@vale.com. PAULO DE FREITAS NOGUEIRA and MARCELO BRESSAN are with the Department of Material and Metallurgical Engineering, Iron Ore Marketing, Vale SA. Av. Dr. Marco Paulo Simon Jardim, 3580, Nova Lima, 34006-270 Brazil.

Manuscript submitted October 9, 2019.

Article published online October 27, 2020. the presence of an oxidized core and a metallic outer layer, the liquid phase moves from the core to the outer layer through pores in the material. As the temperature increases, the amount of liquid phase also increases, penetrating the pores in the outer layer by surface energy, not mechanical energy. In a reducing environment, the liquid phase fills the pores of the outer layer and densifies the metal. ${ }^{[5,6]}$ This densification decreases the contact between the reducing gas and the inner layers of the particle and increases the difficulty of reducing the iron oxide. Consequently, there is a rapid contraction of the burden inside the blast furnace. The softening rate is related to the amount of liquid phase formed, and it is described as a function of temperature. The movement of the liquid phase from the center of a pellet to the outer layers generates voids in the pellet nucleus that decrease its mechanical support and result in structural collapse. ${ }^{[6,7]}$ The consequence of this phenomenon is a rapid contraction of the burden inside the blast furnace. This study validated the mechanism by which the liquid phase is transferred from the core to the surface layers by evaluating microstructural aspects of the process using iron ore samples subjected to interrupted softening and melting experiments.

In this study, the effects of $\mathrm{MgO}$ and $\mathrm{CaO}$ additives on the reduction swelling behavior of different pellets were investigated. $\mathrm{MgO}$ can be dissolved in $\mathrm{FeO}_{1.05}$, forming $\left[(1-x) \mathrm{MgO} \cdot \mathrm{Fe} \mathrm{O}_{x} \mathrm{O} \cdot \mathrm{Fe}_{2} \mathrm{O}_{3}\right.$ and reducing the migration rate of $\mathrm{Fe}^{2+[4]} \mathrm{A}$ subsequent increase in the basicity of the pellet contributes to an increase in the 
softening temperature. ${ }^{[8]}$ An increase of $\mathrm{MgO}$ content in pellets alters the softening temperature and leads to a rise in the dripping temperature. ${ }^{[4,9]}$ Another beneficial effect of $\mathrm{MgO}$ is that it increases the viscosity of the slag at $1450{ }^{\circ} \mathrm{C}$. However, $\mathrm{MgO}$ decreases the viscosity at higher temperatures so that the slag drips together with the metal.

\section{A. Softening and Melting Experiments}

Several studies have attempted to replicate the conditions in the melting and softening zones of blast furnaces. Before softening begins, iron oxides are pre-reduced to the level of wüstite $(\mathrm{O} / \mathrm{Fe} \approx 1.05)$. After a period corresponding to the residence time of the charge in the thermal and chemical reserve zones, thermodynamic conditions contribute to the formation of a superficial layer of metallic iron. ${ }^{[10,11]}$ Consequently, a slight contraction of the burden occurs.

The second phase begins with a more significant deformation of the burden, which is typically accompanied by a decrease in the rate of reduction. Although the burden components deform individually, the macro pores remain open, lowering the magnitude of the pressure drop during this stage of the process. Deformation is a function of the formation of a liquid phase. ${ }^{[5,6]}$

The third phase begins with the formation of a liquid phase, in which the liquid slag initially contains significant amounts of $\mathrm{FeO}$. As the $\mathrm{FeO}$ content decreases, the melting point of the slag increases, and consequently, its solidification temperature. The magnitude of the pressure drop increases due to a decrease in the porosity of the particles.

In the final stage of the process, liquid drips formed by iron, slag, or both and a strong contraction of the burden are observed. The magnitude of the contraction depends on the amount of liquid phase formed in this temperature range. ${ }^{[10,12]}$ As the liquid drips begin, the magnitude of the pressure drop and the rate of reduction decrease. Some authors have proposed parameters that are considered relevant for evaluating the high-temperature properties of pellets. ${ }^{[13,14]}$

\section{METHODOLOGY}

\section{A. Sample Characterization}

In this study, the softening and melting properties of acidic and basic fluxed pellets were investigated using advanced techniques. Acidic pellets were produced from Brazilian iron ore with a low proportion of flux additions or, in some cases, without fluxes. Basic fluxed pellets were produced with flux additions. The typical fluxes were lime (primarily $\mathrm{CaO}$ ) and dolomite $(\mathrm{CaO}$ and $\mathrm{MgO}$ ).

The materials were collected directly from various industrial pellet plants by increments of sampling over 24 hours when the process and quality parameters were stable. Samples were obtained at the point where burned pellets were discharged after the cooling stage. Pellets having basicity ranging from 0.20 to 1.30 were chosen to ascertain a broader range of product quality. These pellets were produced with or without flux additions. Fluxed pellets fabricated with lime (primarily $\mathrm{CaO}$ ) when there was no $\mathrm{MgO}$ content or dolomite $(\mathrm{CaO}$ and $\mathrm{MgO}$ ) when $\mathrm{MgO}$ content was present.

The pellets selected for this study were subjected to chemical analysis to investigate the impact of chemical composition on high-temperature properties. Pellets were analyzed according to ISO 2597-2:2015 and ISO 9516-1:2003. The following components were determined: total $\mathrm{Fe}, \mathrm{FeO}, \mathrm{SiO}_{2}, \mathrm{Al}_{2} \mathrm{O}_{3}, \mathrm{CaO}, \mathrm{MgO}$, and loss of ignition (LOI). The pellet sizes were also measured.

\section{B. Softening and Melting}

Sixteen pellets (acidic and basic fluxed pellets) with different chemical characteristics were tested using an apparatus built at the Centro de Tecnologia de Ferrosos in Nova Lima (Brazil) belonging to Vale. This equipment includes electronic devices and a layout that facilitates the evaluation of high-temperature properties of pellets. The reproducibility and repeatability of the new equipment were evaluated and found to be satisfactory. The apparatus consists of two heating furnaces that allow the appropriate manipulation of temperature profile and gas composition to achieve conditions in which indirect reduction occurs. Such conditions replicate the phenomena that occur in the upper region of a blast furnace.

The equipment consists of two heating furnaces, one upper (power: $45 \mathrm{~kW}$; maximum temperature: $1600{ }^{\circ} \mathrm{C}$ ) and one lower (power: $55 \mathrm{~kW}$; maximum temperature: $1700{ }^{\circ} \mathrm{C}$ ), as shown in Figure 1(a). The assembly prepared for the test is shown in Figure 1(b). A sample pellet is loaded between two layers of coke in a graphite crucible (100 $\mathrm{mm}$ in diameter and $180 \mathrm{~mm}$ in height) positioned in the central region of the upper furnace. The amount of sample is defined by the height of the sample in the crucible $(70 \mathrm{~mm})$ and the density of the pellet. The coke layers have a thickness of $20 \mathrm{~mm}$, and the bottom of the crucible is designed to allow the dripping of the molten material.

The sample was submitted to the thermal profile established as described above. A thermocouple is located inside the piston that applies the charge to the sample. Each furnace is controlled separately by computational controllers. The upper furnace is controlled by a thermocouple placed near the sample.

In this apparatus, each sample was heated under a flow rate of approximately $34 \mathrm{NN} / \mathrm{min} \mathrm{N}_{2}$ at a heating rate of $10^{\circ} \mathrm{C} / \mathrm{min}$. At $800^{\circ} \mathrm{C}$, a pressure of $98 \mathrm{kPa}$ was applied to the sample. The gas composition by volume was 67 pct $\mathrm{N}_{2}, 29$ pct $\mathrm{CO}$, and 4 pct $\mathrm{H}_{2}$, and the continuous flow rate was $34 \mathrm{NL} / \mathrm{min}$. At $1000{ }^{\circ} \mathrm{C}$, the heating rate of the upper furnace was adjusted to $5{ }^{\circ} \mathrm{C} /$ $\mathrm{min}$, and the heating proceeded until a temperature of $1600{ }^{\circ} \mathrm{C}$. The lower furnace was heated at $10{ }^{\circ} \mathrm{C} / \mathrm{min}$ until a temperature of $1700{ }^{\circ} \mathrm{C}$. The outlet gas was continuously analyzed when the temperature reached $800{ }^{\circ} \mathrm{C}$ and above to determine the reduction degree of the sample. The system monitored the displacement of 


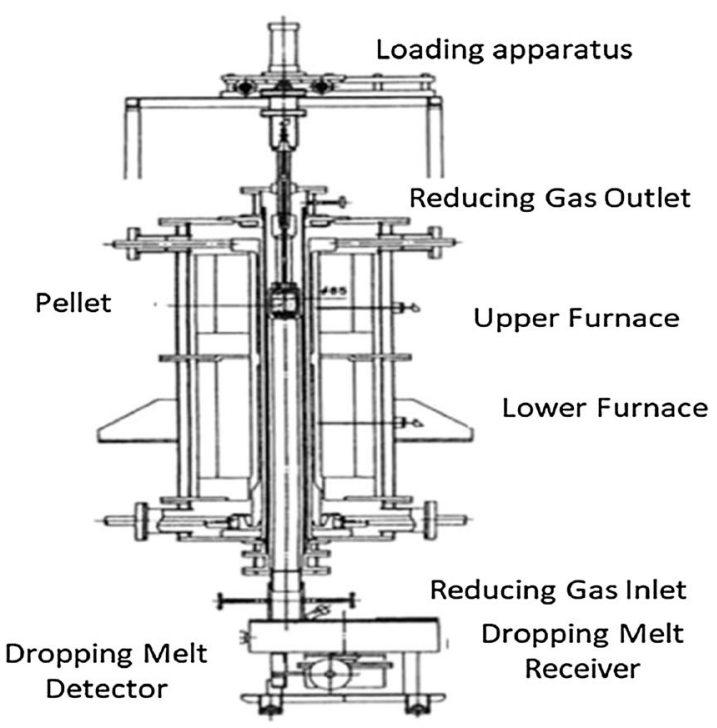

(a)

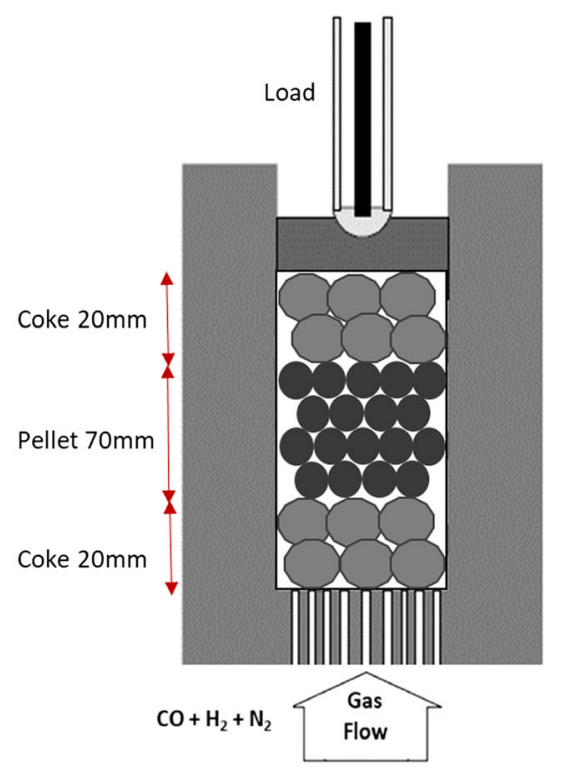

(b)

Fig. 1-(a) Schematic of the furnace used for the softening and melting tests. (b) Arrangement of the crucible with the sample assembly for the test containing one pellet layer between two coke layers to represent the blast furnace burden.

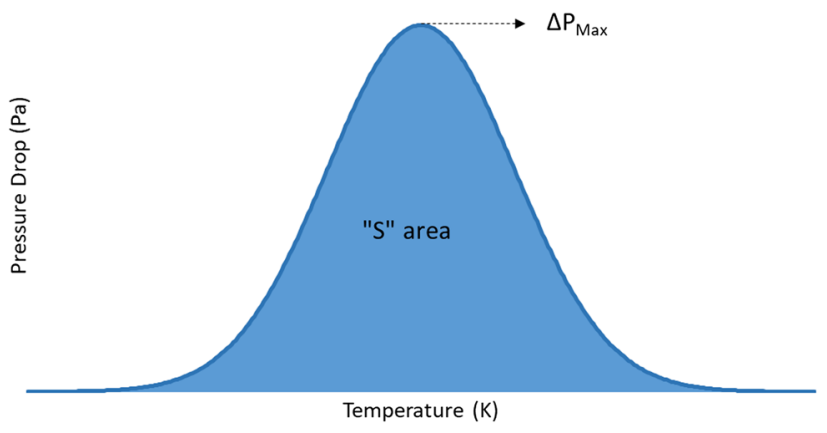

Fig. 2 - Graph of pressure drop vs temperature illustrating the area corresponding to the $S$ value for Eq. [1].

the graphite piston, recording the reduction of volume resulting from the softening and melting stages of the sample. Figure 1 shows the load application system and how the displacement (shrinkage) of the sample was measured. Each experiment was performed three times to obtain a standard deviation for each pellet sample.

The main indexes of the softening and melting tests are as follows:

- Softening temperature $\left(T_{\mathrm{S} 200}\right)$ : temperature corresponding to a pressure drop $(\Delta P)=200 \mathrm{~mm} \mathrm{H}_{2} \mathrm{O}$ (1961 Pa)

- Dripping temperature $\left(T_{\mathrm{D}}\right)$ : dripping temperature

- Cohesive zone temperature range $(\Delta T)$ : temperature range used to calculate the $S$ value

- $S$ value: area under the graph $\Delta P \times T$ (Figure 2), which is expressed by Eq. [1].

$$
S=\int_{T_{\mathrm{S} 200}}^{T_{\mathrm{D}}} \Delta P(T) \partial T
$$

where $\Delta P(T)$ is the pressure drop at temperature $T$. The unit of measurement is $\mathrm{Pa} \cdot \mathrm{K}$. Figure 2 shows the behavior of the $S$ value graphically.

- Maximum pressure drop $\left(\Delta P_{\mathrm{Max}}\right)$ : the maximum $\Delta P$ observed during a test

- Reduction degree $\left(R_{\mathrm{S} 200}\right)$ : reduction degree as the temperature approaches $T_{\mathrm{S} 200}$

\section{RESULTS AND DISCUSSION}

\section{A. Chemical Analysis}

The chemical compositions (wt. pct) and binary $\left(B_{2}=\mathrm{CaO} / \mathrm{SiO}_{2}\right)$ and ternary $\left(B_{3}=\mathrm{CaO}+\mathrm{MgO}\right] /$ $\left.\mathrm{SiO}_{2}\right)$ basicity, are listed in Table I. Each compound forms differentiated phases that directly affect the softening and melting properties. According to studies on blast furnace cohesive zones, the softening and melting temperatures are directly related to the ternary basicity, $B_{3}{ }^{[6-8]}$ Chemical composition is among the primary parameters that affect the $R_{\mathrm{S} 200}$ of pellets during hot metal production. ${ }^{[4,12,15]}$

Therefore, it is necessary to analyze different pellet basicities and chemical compositions to verify if chemical composition affects the softening and melting properties of these pellets. Previous reports concluded that increases in $\mathrm{MgO}, \mathrm{CaO}$, and $\mathrm{SiO}_{2}$ form different minerals that affect the softening and melting properties.

Figure 3 shows a phase diagram of $\mathrm{CaO}-\mathrm{SiO}_{2}-\mathrm{MgO}$ with 10 pct $\mathrm{Al}_{2} \mathrm{O}_{3}$ that was calculated using the FactSage software and thermodynamic databases, version 5.2. An increase in the $\mathrm{CaO} / \mathrm{SiO}_{2}$ ratio leads to the formation of compounds with higher liquidus temperatures. This phenomenon suggests that when the $\mathrm{CaO}$ content decreases, the melting point temperature 
decreases, as shown in Figure 3. As previously mentioned, the slag that forms in the central region of the particle is rich in wüstite and moves through the pores by the capillarity, filling them and preventing reduction. Therefore, if there is a sufficient level of wüstite in the center of the particle, a solution to avoid the formation of primary slag would be to control the amount of silica available for reaction with wüstite. This control can be achieved chemically by favoring the formation of calcium silicate, which makes the silica unavailable to react with wüstite.

The phase diagram in Figure 3 also reveals the impact of $\mathrm{MgO}$ on the liquidus temperature. In this case, an increase in $\mathrm{MgO}$ increases the melting temperature due to the formation of compounds such as merwinite. Another consequence of adding $\mathrm{MgO}$ to pellets is the formation of magnesiowüstite, which is beneficial to softening and melting properties.

The ability to predict the formation of the liquid phase improves our understanding of softening and melting phenomena. The initial formation of the liquid phase is vital to the beginning of softening, the $R_{\mathrm{S} 200}$, and the dripping of the liquid phase. Tables I and II show the chemical composition and data obtained from physical tests of softening and melting with all pellet samples. From these values, it is possible to create mathematical correlations between ternary basicity and several softening and melting properties.

As shown in Table II, the pellets A, E, K, and $\mathrm{O}$ presented the highest $\mathrm{S}$ value (area under the curve $\Delta T \times \Delta P)$, indicating that these pellets have a lower permeability during softening and melting inside the blast furnace. The ternary basicity of these pellets was the weakest among those evaluated. Therefore, ternary basicity is directly correlated to softening and melting properties.

The data in Table II also show that $\mathrm{R}_{\mathrm{S} 200}$ is lower than 70 pet when compared to the $R_{\mathrm{S} 200}$ of the actual blast furnace. An explanation for this is that the operational conditions of the laboratory tests are different than those in a blast furnace (e.g., gas composition, the content of metallic burden, and other parameters).

$\mathrm{CO}_{2}$ and $\mathrm{H}_{2} \mathrm{O}$ gases were not used in correlation analysis because the outlet gas was not crucible for this study compared to the other variables listed in Table II.

The images in Figure 4 reveal areas of magnesium ferrite $\left(\mathrm{MgFe}_{2} \mathrm{O}_{4}\right)$ in pellet $\mathrm{L}$, which are not observed in pellet $\mathrm{A}$, due to the presence of $\mathrm{MgO}$ in the chemical composition of pellet $\mathrm{L}$.

This phase contributes to better softening and melting properties, as will be discussed later. $\mathrm{MgFe}_{2} \mathrm{O}_{4}$ leads to the formation of new chemical phases with higher melting points, avoids an increase in liquid phase formation, and contributes to the reduction of the burden. ${ }^{[13]}$

\section{B. Softening and Melting Results}

From the results of chemical analysis and the softening and melting tests, several graphs were constructed to correlate the chemical composition of each pellet with parameters of the softening and melting tests. Among the parameters that are measured in softening and melting tests, $T_{\mathrm{S} 200}, \Delta P$, and $R_{\mathrm{S} 200}$ have been statistically correlated with $B_{2}, B_{3}$, and quarternary basicity, $B_{4}$.

$B_{2}$ and $B_{4}$ were not chosen because these parameters did not show statistically satisfactory correlations with the softening and melting variables mentioned above. Among the parameters provided by the softening and melting tests, $T_{\mathrm{S} 200}, \Delta P, R_{\mathrm{S} 200}$, and $T_{\mathrm{D}}$ were statistically correlated with $B_{3}$.

In pellets with a high $\mathrm{MgO} / \mathrm{SiO}_{2}$ ratio, softening and melting properties are significantly affected because $\mathrm{MgO}$ remains unslagged and primarily exists in wüstite as a FeO-MgO solid solution. ${ }^{[12,15,16]}$ As the amount of $\mathrm{MgO}$ increases, the primary minerals of the residual slag change from $2 \mathrm{CaO} \cdot \mathrm{SiO}_{2}$ to merwinite and melilite. The changes in the minerals in the slag phase can explain the trend of the softening-melting characteristic temperatures. ${ }^{[3,16]}$ The softening of the burden starts with the formation of a liquid phase within the microstructure in the nucleus of the reduced particle and not by deformation of the solid phase. ${ }^{[3,13,14]}$ The contraction of the bed is possibly due to the sintering of either wüstite, iron, or both. The liquid phase acts as a lubricant between the wüstite cores and is transferred from the interior of the particle to the superficial layers through the pores. Consequently, voids are generated in the nucleus, reducing its mechanical support and leading to the deformation of the particle. However, an increase in a basic oxide such as $\mathrm{CaO}$ and $\mathrm{MgO}$ leads to the formation of new chemical compounds, altering the solidus/liquidus relationship. This alteration decreases the formation of the liquid phase, which decreases the deformation of the particle. In this context, it is possible to explain why acid pellets have lower $T_{\mathrm{S} 200 \text {, }}$ and basic pellets have higher $T_{\mathrm{S} 200}$.

An increase in $B_{3}$ retards the softening of the pellet, as observed in Figure 5 . The impact of $B_{3}$ on the $T_{\mathrm{S} 200}$ is less substantial for acidic pellets. However, for fluxed pellets, the impact is more significant, as shown by the slope of the curves in Figure 5. An explanation for this conclusion is related to the amount of liquid formation when the temperature increases. Although the $T_{\mathrm{S} 200}$ for acidic pellets is lower due to the formation of a low melting point slag containing $\mathrm{SiO}_{2}, \mathrm{Al}_{2} \mathrm{O}_{3}$, and $\mathrm{FeO}$, the pellets containing fluxes have a higher $T_{\mathrm{S} 200}$ and narrower softening/ melting range. Therefore, an increase in basicity tends to increase the meltdown temperature.

Figure 6 illustrates how $\Delta P$ decreases with an increase in $B_{3}$. This decrease occurs because of the amount of slag former in the core of the particle. The softening of the burden begins with the formation of the liquid phase within the microstructure of the nucleus of the reduced particle. The voids generated in the nucleus reduce its mechanical stability, leading to the deformation of the particle. However, in the presence of $\mathrm{MgO}$, pre-reduced wüstite forms a compound with magnesium called magnesium wüstite. When the liquid slag forms and makes contact with silica, it releases $\mathrm{Mg}^{2+}$ cations. ${ }^{[2-4]}$ The liquid solidifies because the $\mathrm{Mg}^{2+}$ cations and the remaining liquid slag has a high $\mathrm{CaO}$ content. Consequently, an increase in $\mathrm{CaO}$ and $\mathrm{MgO}$ content leads to an increase in the softening and melting temperature. As a result of this phenomenon, there is an increase in bed permeability due 
Table I. Chemical Analysis and Basicity of the Pellet Samples (Weight Percent)

\begin{tabular}{|c|c|c|c|c|c|c|c|c|}
\hline Pellet & $\mathrm{Fe}$ & $\mathrm{FeO}$ & $\mathrm{CaO}$ & $\mathrm{SiO}_{2}$ & $\mathrm{Al}_{2} \mathrm{O}_{3}$ & $\mathrm{MgO}$ & $\mathrm{B}_{2}$ & $\mathrm{~B}_{3}$ \\
\hline A & 66.16 & 0.25 & 0.82 & 3.05 & 1.00 & 0.08 & 0.3 & 0.3 \\
\hline B & 65.17 & 0.23 & 2.99 & 2.50 & 0.80 & 0.06 & 1.2 & 1.2 \\
\hline $\mathrm{C}$ & 65.80 & 1.19 & 2.42 & 2.36 & 0.67 & 0.03 & 1.0 & 1.0 \\
\hline D & 66.27 & 0.48 & 1.83 & 2.22 & 0.67 & 0.03 & 0.8 & 0.8 \\
\hline $\mathrm{E}$ & 63.83 & 0.22 & 1.29 & 5.04 & 0.74 & 0.49 & 0.3 & 0.4 \\
\hline $\mathrm{F}$ & 65.10 & 0.21 & 2.54 & 2.44 & 1.00 & 0.09 & 1.0 & 1.1 \\
\hline $\mathrm{G}$ & 64.49 & 0.30 & 2.99 & 3.14 & 0.98 & 0.03 & 1.0 & 1.0 \\
\hline $\mathrm{H}$ & 64.77 & 0.23 & 2.95 & 3.39 & 1.00 & 0.08 & 0.9 & 0.9 \\
\hline I & 65.15 & 0.52 & 2.82 & 2.82 & 0.77 & 0.07 & 1.0 & 1.0 \\
\hline $\mathbf{J}$ & 63.87 & 0.26 & 2.80 & 4.18 & 1.18 & 0.07 & 0.7 & 0.7 \\
\hline $\mathrm{K}$ & 63.83 & 0.22 & 1.29 & 5.04 & 0.74 & 0.49 & 0.3 & 0.4 \\
\hline $\mathrm{L}$ & 62.77 & 0.38 & 3.84 & 4.49 & 0.68 & 0.80 & 0.9 & 1.0 \\
\hline M & 66.20 & 0.40 & 2.44 & 2.26 & 0.50 & 0.05 & 1.1 & 1.1 \\
\hline $\mathrm{N}$ & 65.17 & 0.23 & 2.99 & 2.50 & 0.80 & 0.06 & 1.2 & 1.2 \\
\hline $\mathrm{O}$ & 63.80 & 1.03 & 2.58 & 5.17 & 0.30 & 0.18 & 0.5 & 0.5 \\
\hline $\mathrm{P}$ & 66.87 & 0.15 & 1.75 & 1.39 & 0.50 & 0.04 & 1.3 & 1.3 \\
\hline
\end{tabular}

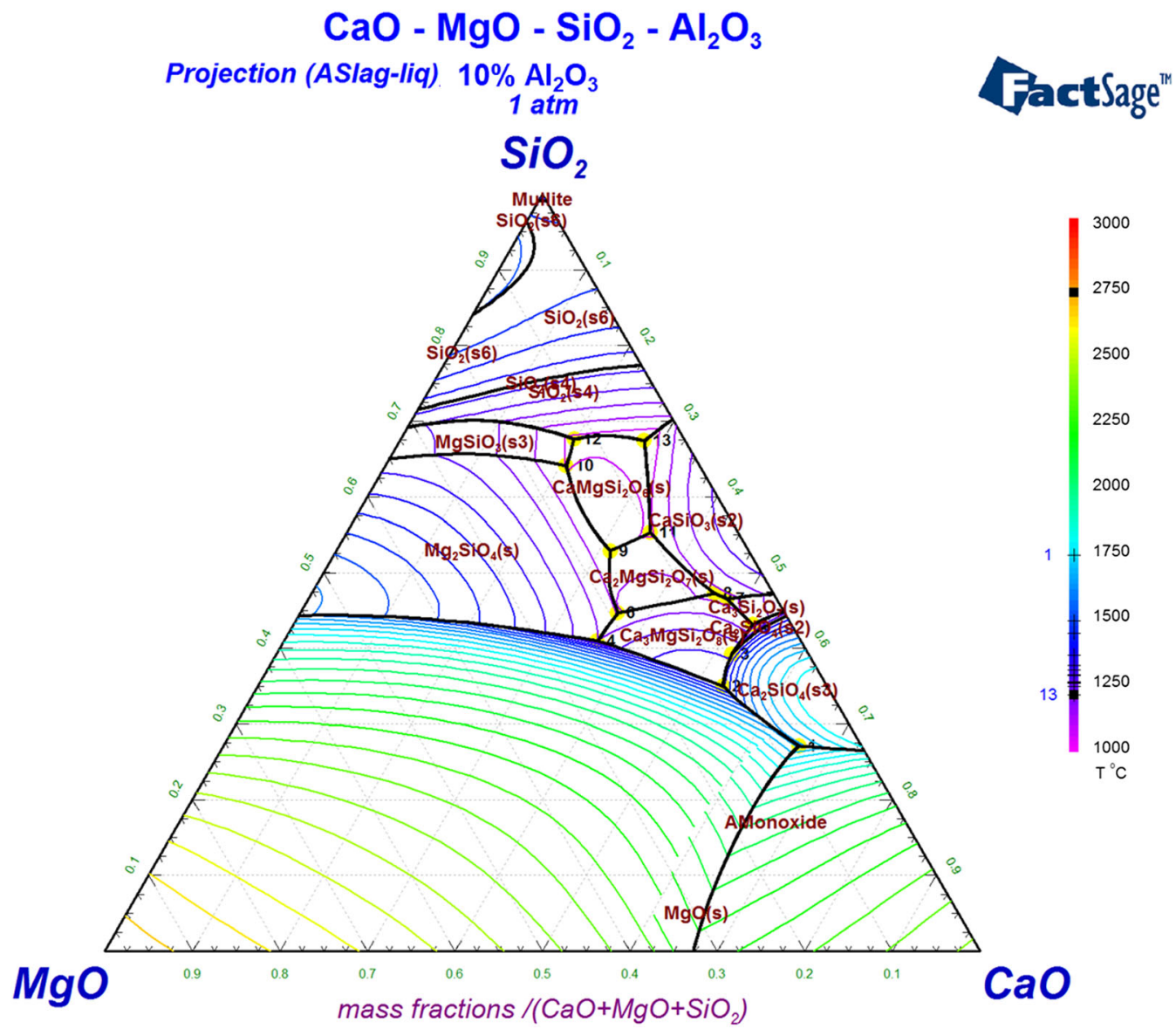

Fig. 3 - Calculated isotherms of the $\mathrm{CaO}-\mathrm{SiO}_{2}-\mathrm{MgO}$ with 10 pct $\mathrm{Al}_{2} \mathrm{O}_{3}$ pseudo-quaternary phase, from 1200 to $2750{ }^{\circ} \mathrm{C}$, using the $\mathrm{FactSage}$ thermochemical software and databases, version 5.2.

to the retardation of burden softening. Therefore, this mechanism explains why an increase in $B_{3}$ suggests that the softening and melting temperature increases and contributes to a decrease in the thickness of the cohesive zone and, consequently, a reduction in $\Delta P$.
Figure 7 shows the effect of $B_{3}$ on $R_{\mathrm{S} 200}$ : the higher the $B_{3}$, the higher the $R_{\mathrm{S} 200}$ of iron. This occurs because the liquid phase formed in the core of the pellet fills the pores, causing the densification of the metal layer. Initially, slag forms in the central region of the particle, 
Table II. Softening and Melting Properties of Each Pellet Obtained by Physical Tests and the Corresponding Standard Deviation $(\sigma)$

\begin{tabular}{|c|c|c|c|c|c|c|c|c|c|c|}
\hline Pellet & $S\left(\mathrm{~kg} \cdot \mathrm{K} \cdot \mathrm{m}^{-2}\right)$ & $\sigma\left(\mathrm{kg} \cdot \mathrm{K} \cdot \mathrm{m}^{-2}\right)$ & $T_{\mathrm{S} 200}(\mathrm{~K})$ & $\sigma(\mathrm{K})$ & $\Delta T(\mathrm{~K})$ & $\sigma(\mathrm{K})$ & $R_{\mathrm{s} 200}(\mathrm{pct})$ & $\sigma(\mathrm{pct})$ & $\Delta P_{\max }(\mathrm{Pa})$ & $\sigma(\mathrm{Pa})$ \\
\hline A & 13138 & 1.97 & 1315 & 0.96 & 334 & 0.97 & 36.1 & 0.97 & 64956 & 19.74 \\
\hline B & 1111 & 1.98 & 1504 & 0.98 & 111 & 0.96 & 64.1 & 0.82 & 22688 & 19.80 \\
\hline $\mathrm{C}$ & 2466 & 1.96 & 1420 & 0.94 & 183 & 0.94 & 60.1 & 0.76 & 26619 & 19.67 \\
\hline $\mathrm{D}$ & 3439 & 2.98 & 1388 & 0.98 & 226 & 0.97 & 56.1 & 0.98 & 35121 & 19.89 \\
\hline $\mathrm{E}$ & 10858 & 1.99 & 1336 & 0.98 & 273 & 0.99 & 46.1 & 0.99 & 73304 & 19.95 \\
\hline $\mathrm{F}$ & 5974 & 3.98 & 1414 & 0.96 & 259 & 0.98 & 57.1 & 0.98 & 34792 & 19.82 \\
\hline G & 3029 & 1.97 & 1378 & 1.03 & 243 & 1.07 & 55.1 & 0.97 & 26942 & 19.71 \\
\hline $\mathrm{H}$ & 6784 & 1.97 & 1359 & 0.96 & 246 & 0.96 & 59.1 & 0.97 & 46707 & 19.77 \\
\hline I & 5067 & 3.96 & 1396 & 0.94 & 223 & 0.96 & 59.1 & 0.96 & 38839 & 19.64 \\
\hline $\mathbf{J}$ & 7515 & 1.96 & 1378 & 0.94 & 274 & 1.96 & 46.1 & 0.96 & 52233 & 19.69 \\
\hline $\mathrm{K}$ & 11836 & 4.97 & 1335 & 0.46 & 274 & 2.95 & 49.1 & 0.97 & 80018 & 19.75 \\
\hline $\mathrm{L}$ & 7952 & 1.96 & 1395 & 1.08 & 229 & 1.06 & 63.1 & 0.96 & 44687 & 19.62 \\
\hline M & 1389 & 7.96 & 1459 & 1.06 & 146 & 1.04 & 66.1 & 0.85 & 20868 & 19.66 \\
\hline $\mathrm{N}$ & 1658 & 1.97 & 1470 & 1.05 & 157 & 0.97 & 63.1 & 0.97 & 23734 & 19.72 \\
\hline $\mathrm{O}$ & 8612 & 4.95 & 1337 & 0.95 & 232 & 0.98 & 52.1 & 0.95 & 56291 & 19.59 \\
\hline $\mathrm{P}$ & 2175 & 2.00 & 1528 & 2.00 & 205 & 2.00 & 61.1 & 2.00 & 28844 & 20.09 \\
\hline
\end{tabular}

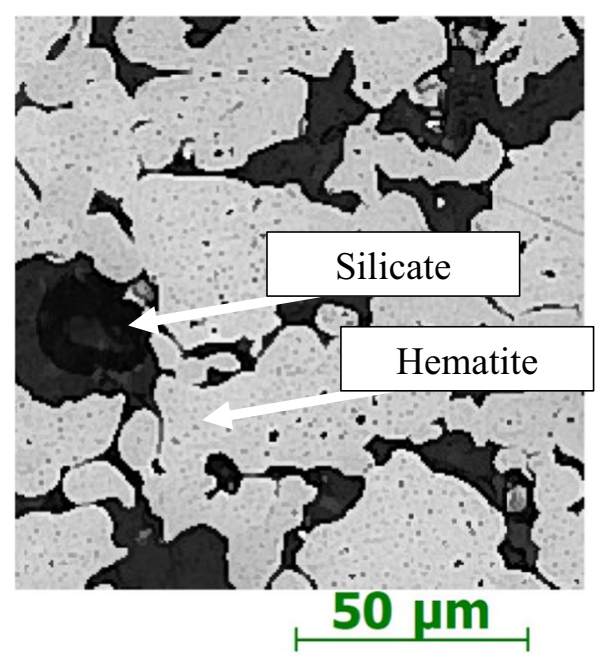

(a) Pellet A

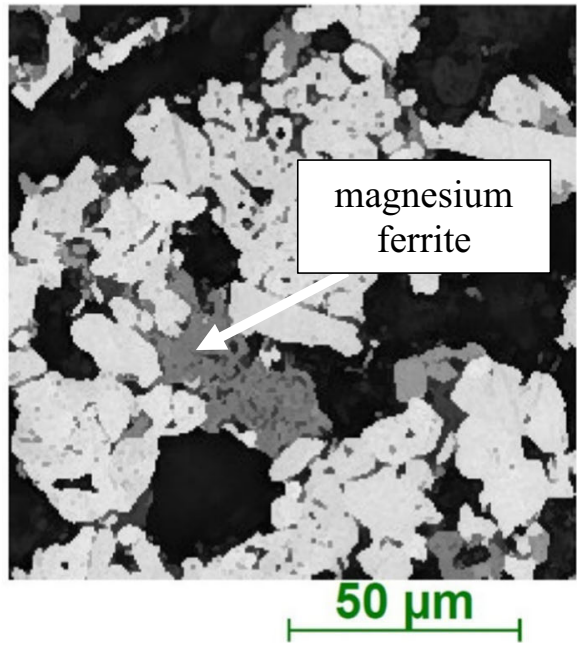

(b) Pellet L

Fig. 4-Polished cross-sections of acidic- and basic-fluxed pellets, revealing the presence of silicate in panel (a), which represents pellet A, and magnesium ferrite in panel $(b)$, which represents pellet L.

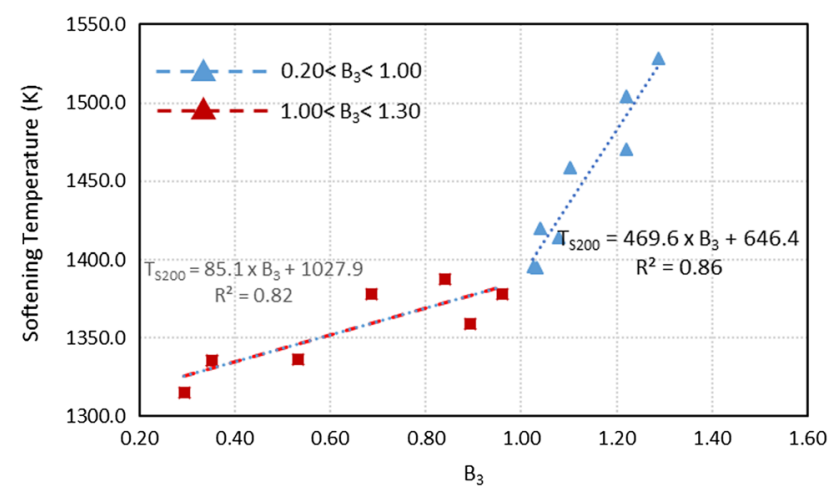

Fig. 5-Statistical correlation between the softening temperature $\left(T_{\mathrm{S} 200}\right)$ and the ternary basicity $\left(B_{3}\right)$.

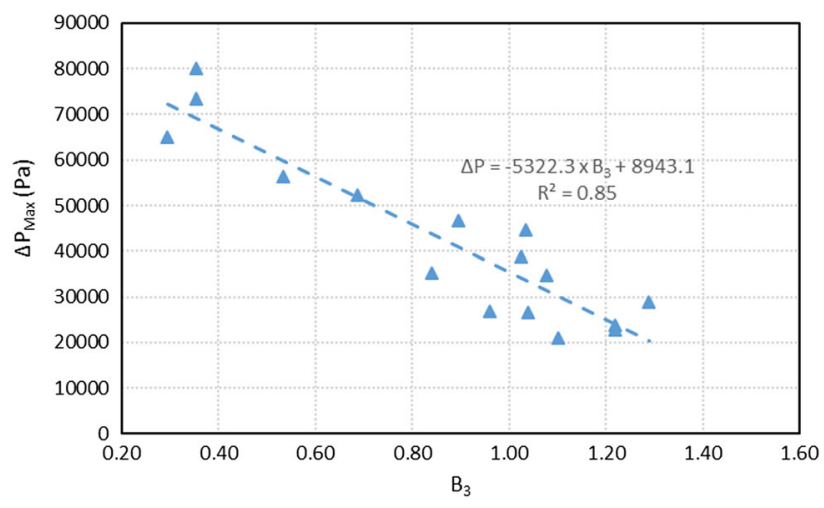

Fig. 6-Pressure drop $\left(\Delta P_{\text {Max }}\right)$ as a function of the ternary basicity $\left(B_{3}\right)$. Based on this plot, a mathematical correlation between these variables is observed. 


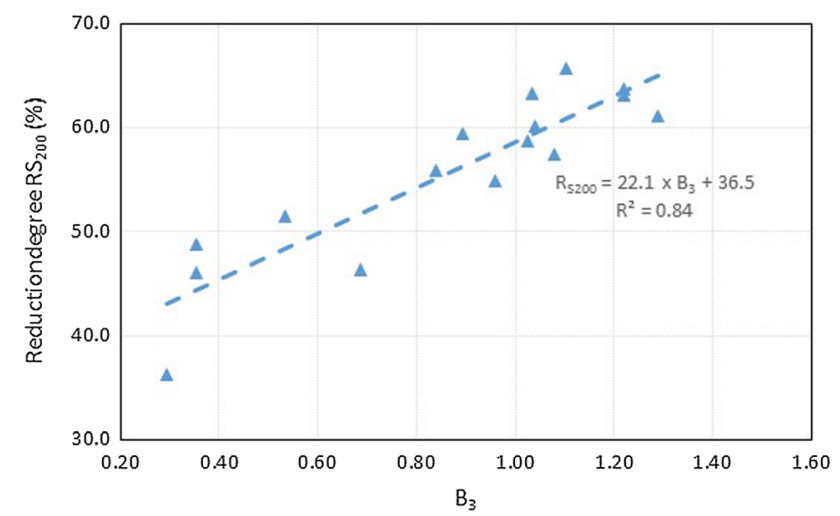

Fig. 7-Influence of the ternary basicity $\left(B_{3}\right)$ on the reduction degree $\left(R_{\mathrm{S} 200}\right)$ of pellets.

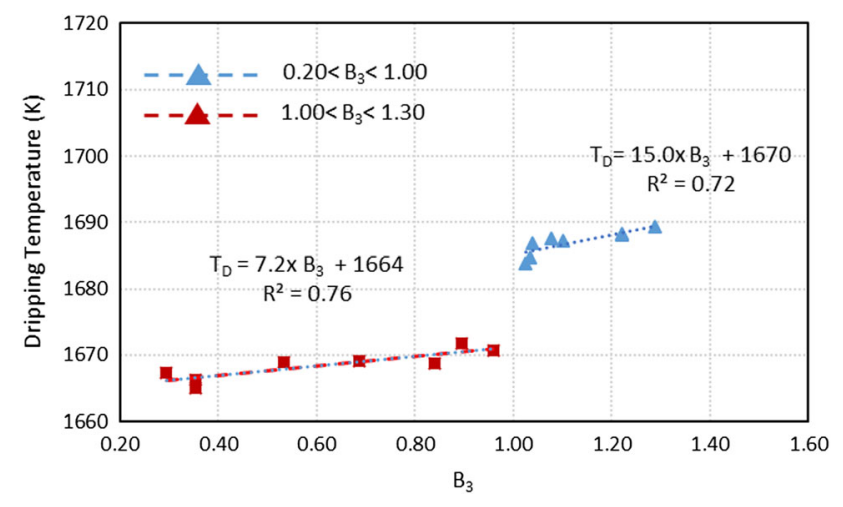

Fig. 8-Statistical correlation between the dripping temperature $\left(T_{\mathrm{D}}\right)$ and the ternary basicity $\left(B_{3}\right)$.

which is rich in wüstite $(\mathrm{FeO})$. Slag moves through the pores by their capillarity, filling them and decreasing iron ore reduction..$^{[15,17,18]} \mathrm{An}$ increase in $\mathrm{CaO}$ and $\mathrm{MgO}$ content causes the formation of new chemical compounds with higher melting points, avoids liquid phase formation, and increases iron ore reduction. This mechanism decreases the $R_{\mathrm{S} 200}$ of the inner layers of the particles.

It is necessary to understand the effects of $\mathrm{CaO}$ and $\mathrm{MgO}$. $\mathrm{CaO}$ tends to form a higher melting point slag; however, its impact on iron reduction is attenuated because $\mathrm{CaO}$-fluxed pellets lead to the formation of dicalcium silicate $\left(2 \mathrm{CaO} \cdot \mathrm{SiO}_{2}\right)$, which does not contribute to the $R_{\mathrm{S} 200}$. In contrast, the addition of $\mathrm{MgO}$ leads to the formation of merwinite and eventually magnetite-magnesioferrite, which enhance the properties. The enhancement occurs because the diffusion of $\mathrm{Mg}^{2+}$ into the solid wüstite phase increases its melting temperature and that of the slag liquidus due to the depletion of cations that diffused into wüstite. ${ }^{[16,19]}$ Therefore, $\mathrm{MgO}$ contributes to increases in the melting temperature and iron ore reduction due to the formation of specific chemical compounds, as explained in Figure 3.
The last parameter analyzed was the $T_{\mathrm{D}}$. Figure 8 shows that an increase in $\mathrm{CaO}$ and $\mathrm{MgO}$ has a minimal impact on the $T_{\mathrm{D}}$ for fluxed pellets. For acidic pellets, $B_{3}$ has a less substantial effect on the $T_{\mathrm{D}}$. As the liquid phase envelops the solid oxide particles, it becomes a semi-solid material, where the liquid slag acts as a lubricant for the remaining particles. After the liquid slag in the core has lubricated all the oxide particles, the mechanical strength of the core decreases, and the resistance to deformation is determined by the iron shell. The ability of the metallic shell to contain the molten oxide depends primarily on its cross-section, which is correlated to the $R_{\mathrm{S} 200}{ }^{[20]}$ When the liquid volume fraction increases with temperature, it will reach a point where the iron shell can no longer hold it. Reaching this point initiates dripping of the liquid slag from the burden material (i.e., the $T_{\mathrm{D}}$ ). 1 The $T_{\mathrm{D}}$ is determined by the shell strength, which is ultimately proportional to the $R_{\mathrm{S} 200}$. Therefore, an increase in $\mathrm{CaO}$ and $\mathrm{MgO}$ increases the $T_{\mathrm{D}}$, but the effect is negligible, as shown in Figure 6. ${ }^{[21-23]}$

Therefore, by comparing Figure 5 with Figure 8, it is observed that $B_{3}$ has a more substantial impact on $T_{\mathrm{S} 200}$ than $T_{\mathrm{D}}$. Thus, it suggests a shorter softening/melting range for fluxed pellets, which is beneficial to the blast furnace process because the thickness of the cohesive zone is narrower.

\section{CONCLUSIONS}

From the results given, the following conclusions can be made regarding the softening and melting properties of acidic and basic pellets:

1. Iron ore-fluxed pellets exhibit better softening and melting characteristics relative to acidic pellets. Basic fluxed pellets exhibit higher resistance to the initiation of softening, which leads to premature formation of the liquid phase. In terms of blast furnace operation, fluxed pellets tend to be in solid phase within a larger region inside the reactor relative to acidic pellets.

2. The $R_{\mathrm{S} 200}$ of fluxed pellets is higher than that of acidic pellets. The addition of $\mathrm{MgO}$ to acidic and fluxed pellets at all basicity levels increases reducibility by forming high melting point slag, which inhibits liquid phase formation and keeps the pores of the particles open to reducing gas. Therefore, an increase in $\mathrm{MgO}$ and $\mathrm{CaO}$ content (higher $B_{3}$ ) leads to an increase in the melting point. This increase occurs because of the formation of new compounds (e.g., calcium silicate and merwinite), which leads to a high $R_{\mathrm{S} 200}$. This mechanism contributes to lower fuel consumption in the blast furnace.

3. The $T_{\mathrm{D}}$ is proportional to $B_{3}$. However, the effect of $B_{3}$ on $T_{\mathrm{S} 200}$ is more substantial than its effect on $T_{\mathrm{D}}$. This observation suggests a narrower softening/ melting range, which is advantageous to the blast furnace process. 
4. From the data obtained in this study, it can be concluded that basic fluxed pellets are beneficial to the efficiency and operational stability of blast furnaces because they minimize the thickness of the cohesive zone.

\section{ACKNOWLEDGMENTS}

We would like to thank the Centro de Tecnologia de Ferrosos (Vale SA) for providing equipment essential for the metallurgical and chemical testing.

\section{OPEN ACCESS}

This article is licensed under a Creative Commons Attribution 4.0 International License, which permits use, sharing, adaptation, distribution and reproduction in any medium or format, as long as you give appropriate credit to the original author(s) and the source, provide a link to the Creative Commons licence, and indicate if changes were made. The images or other third party material in this article are included in the article's Creative Commons licence, unless indicated otherwise in a credit line to the material. If material is not included in the article's Creative Commons licence and your intended use is not permitted by statutory regulation or exceeds the permitted use, you will need to obtain permission directly from the copyright holder. To view a copy of this licence, visit http://creativec ommons.org/licenses/by/4.0/.

\section{REFERENCES}

1. T. Lia, C. Suna, X. Liu, S. Song, and Q. Wanga: Ironmak. Steelmak., 2018, vol. 45, pp. 755-63.
2. H.J. Zhang, X.F. She, Y.H. Han, J.S. Wang, F.B. Zeng, and O.G. Xue: J. Iron Steel Res. Int., 2015, vol. 22, pp. 297-303.

3. M. Iljana, A. Kemppainen, T. Paananen, O. Mattila, E.-P. Heikkinen, and T. Fabritius: ISIJ Int., 2016, vol. 56, pp. 1705-14.

4. X.W. An, J.S. Wang, R.Z. Lan, Y.H. Han, and Q.G. Xue: J. Iron Steel Res. Int., 2013, vol. 20, pp. 11-16.

5. P.F. Nogueira and R.J. Fruehan: Metall. Mater. Trans. B, 2004, vol. 35 , pp. 829-38.

6. A. A. Castro: Masters Thesis, Universidade Federal de Ouro Preto, Pós-Graduação em Engenharia de Materiais, 2006, pp. $21-60$.

7. P. Kaushik and R.J. Fruehan: Ironmak. Steelmak., 2006, vol. 33, pp. 520-28.

8. J. Liu, G. Cheng, Z. Liu, M. Chu, and X. Xue: Int. J. Miner. Process., 2015, vol. 142, pp. 113-18.

9. U. Leimalm, S. Forsmo, A. Dahlstedt, L.S. Ökvist, and B. Björkman: ISIJ Int., 2010, vol. 50, pp. 1396-405.

10. V.D. Eisenhuttenleute: Slag Atlas, 2nd ed., Verlag Stahleisen GmbH, Düsseldorf, 1995, p. 156.

11. W.J. Yang, Z.Y. Zhou, A.B. Yu, and D. Pinson: Powder Technol., 2015, vol. 279, pp. 134-45.

12. P. Barnaba: Ironmak. Steelmak., 1985, vol. 12, pp. 53-63.

13. H.-C. Chuan: Mater. Trans., 2009, vol. 50, p. 1448.

14. T. Bakker and R.H. Herema: Ironmaking Conference Proceedings Int., ICSTI, Warrendale, 1998, pp. 597.

15. V.J. Ritz, H.A. Kortmann, and K. Koch: Ironmaking Conference Proceedings Int., ICSTI, Warrendale, 1998, pp. 1635-1654.

16. S. Dwarapudi, T.K. Ghosh, V. Tathavadkar, M.B. Denys, D. Bhattacharjee, and R. Venugopal: Int. J. Miner. Process., 2012, vol. 112 , pp. $55-62$.

17. M. Guha and M. Sinha: ISIJ Int., 2015, vol. 55, p. 2033.

18. T. Bakker: Ph.D. Thesis, Delft University of Technology, 1999.

19. G.H. Li, Z.K. Tang, Y.B. Zhang, Z.X. Cui, and T. Jiang: Ironmak. Steelmak., 2010, vol. 37, pp. 393-97.

20. A. Kemppainen, K.I. Ohno, M. Iljana, O. Mattila, T. Paananen, E.P. Heikkinen, T. Maeda, K. Kunitomo, and T. Fabritius: ISIJ Int., 2015, vol. 55, pp. 2039-46.

21. V. Shatokha and O. Velychko: High Temp. Mater. Process. Isr., 2012, vol. 31, pp. 215-20

22. X.-W. An, J.-S. Wang, R.-Z. Lan, Y.-H. Han, and Q.-G. Xue: $J$. Iron Steel Res. Int., 2013, vol. 20, p. 11

23. L. Lu, J. Pan, and D. Zhu: Iron Ore: Mineralogy, Processing and Environmental Sustainability, Woodhead Publishing, Cambridge, Cambridge, 2015, p. 17.

Publisher's Note Springer Nature remains neutral with regard to jurisdictional claims in published maps and institutional affiliations. 